\title{
Sex differences in relationships between metabolic syndrome components and factors associated with health-related quality of life in middle-aged adults living in the community: a cross-sectional study in Taiwan
}

Cheng-Chieh Liu ${ }^{1 \dagger}$, Hsiao-Ting Chang ${ }^{2,3 \dagger}$, Shu-Chiung Chiang ${ }^{4}$, Harn-Shen Chen ${ }^{3,5}$, Ming-Hwai Linn ${ }^{2,3}$, Tzeng-Ji Chen ${ }^{2,3,4}$ and Shinn-Jang Hwang ${ }^{2,3 *}$

\begin{abstract}
Background: Metabolic syndrome (MetS) is a widespread condition with important effects on public health, in general. There is a lack of relevant research on possible sex differences in the relationship between MetS and health-related quality of life (HRQoL) and also the sex differences in factors associated with HRQoL. The aims of this study were to identify: 1) whether women exhibit greater negative impacts on physical domain HRQoL from MetS compared with men; 2) whether women exhibit greater mental domain impacts compared with men; and 3) whether factors associated with HRQoL scores are different for men and women.

Methods: This cross-sectional study was conducted in Taipei, Taiwan. Using random sampling, a total of 906 participants aged 35-55 years were recruited. MetS was defined according to the MetS criteria for the Taiwanese population, and HRQoL were assessed using physical component summary (PCS) and mental component summary (MCS) scores of the Short Form Health Survey (SF-36), Taiwan version. Demographics, physical activity, medical history, and blood tests as covariates were recorded and checked. The associations were assessed by multiple linear regression.

Results: After adjusting for covariates, women but not men with more components of MetS had significantly lower PCS scores $(\beta=-0.542, p=0.036)$. The number of components of MetS was not a significant factor in MCS score differences between the sexes. Furthermore, there were sex differences regarding age, education level, physical activity, and smoking status in association with PCS scores. For MCS scores, sex differences were found in education level, marital status, and habits of smoking and alcohol consumption.

Conclusions: There were sex differences in the relationships between metabolic syndrome components and factors associated with HRQoL among middle-aged adults living in the community in Taiwan. Further research should be conducted to investigate mechanisms of these sex differences.
\end{abstract}

Keywords: Health-related quality of life, Metabolic syndrome, Physical activity, Sex differences, SF-36

\footnotetext{
*Correspondence: sjhwang@vghtpe.gov.tw

${ }^{\dagger}$ Equal contributors

2Department of Family Medicine, Taipei Veterans General Hospital, No. 201,

Section 2, Shipai Road, Beitou District, Taipei, Taiwan

${ }^{3}$ School of Medicine, National Yang-Ming University, Taipei, Taiwan

Full list of author information is available at the end of the article
}

(c) The Author(s). 2018 Open Access This article is distributed under the terms of the Creative Commons Attribution 4.0 International License (http://creativecommons.org/licenses/by/4.0/), which permits unrestricted use, distribution, and reproduction in any medium, provided you give appropriate credit to the original author(s) and the source, provide a link to the Creative Commons license, and indicate if changes were made. The Creative Commons Public Domain Dedication waiver (http://creativecommons.org/publicdomain/zero/1.0/) applies to the data made available in this article, unless otherwise stated. 


\section{Background}

The term metabolic syndrome (MetS) refers to a collection of conditions, including central obesity, elevated triglyceride, elevated blood pressure, fasting hyperglycemia, and low levels of high-density lipoprotein cholesterol (HDL-C). MetS is regarded as a major public health issue in many developed and developing countries [1]. Many studies have shown that MetS is associated with increased risks of diabetes, cardiovascular diseases, cerebrovascular diseases, poorer quality of life, and mortality [2-5]. According to the 1999-2000 National Health and Examination Survey (NHANES) in the United States, the age-adjusted prevalence of MetS was 27.0\%, according to Adult Treatment Panel III (ATP III) criteria [6]. A systemic review conducted in 2013 showed that the weighted mean general prevalence of MetS in Brazil was $29.6 \%$ [7]. In mainland China, a meta-analysis of 35 studies that collectively analyzed data from 2000 to 2015 for 2,26,653 Chinese participants more than 15 years old found that the pooled prevalence of MetS was 24.5\% [8]. In Taiwan, according to the 2005-2008 Nutrition and Health Survey in Taiwan [9], the prevalence of MetS among all people over 19 years of age was $28.5 \%$; the prevalence in women was $31.5 \%$ and it was $25.5 \%$ in men, with prevalence generally increasing with age. According to a 2005 study, the overall prevalence of MetS in Japan was $5.3 \%$, with rates of $4.4 \%$ among women and $6.2 \%$ among men. The low rate of MetS in Japan might be related to the fact that the Japanese population generally consumes a balanced diet, engages in brisk walking and regular exercise, and works 3 to $7 \mathrm{~h}$ a day [10]. The prevalence of MetS in Taiwan is therefore similar to rates in the United States, Brazil, and mainland China and are substantially higher than those in Japan. Furthermore, there is an increasing prevalence of MetS in the middle-aged population of Taiwan (i.e., those aged 3065 years), especially men [11].

Health-related quality of life (HRQoL) is a broad, multidimensional concept that usually includes subjective evaluations of both positive and negative aspects of life [12]. Health has traditionally been measured narrowly and from a deficit perspective, often using measures of morbidity or mortality. Owing to advances in modern medicine and improved social welfare, however, average human life expectancy has increased. At the same time, people have gradually noted that health is no longer viewed as purely a matter of longevity but is now also seen as a multidimensional construct that includes physical, mental, and social domains [13]. As such, the ways in which health outcomes are measured should assess the health of a population not only with the aim of saving lives but also to improve quality of life among the population.

Previous studies on associations between MetS and HRQoL have found that participants who exhibit more components of MetS generally have a poorer quality of life $[14,15]$. Regarding sex differences between the association of MetS components and HRQoL, there have been few studies that have considered differing HRQoL impacts among men and women. A previous study of the general population in Iran indicated that MS is associated with poor HRQoL in women but not in men, and that this association is formed mainly in relation to physical rather than mental health [14]. Another study in Korea found that MS has a significant negative impact on the HRQoL of middle-aged Korean women but no significant impact on that of middle-aged Korean men [16]. The negative impacts of MetS on women might be related to several factors, including the level of physical morbidity, the prevalence of chronic conditions, and the level of pain [16]. Another study in Japan examining relationships between HRQoL and clustering of MS diagnostic components in participants aged 19-69 years found that the number of components of MetS was negatively associated with the general health score of HRQoL but positively associated with the mental health score of HRQoL in both men and women [15].

Given that MetS is a widespread condition with important public health effects in general, and considering the lack of relevant research on possible sex differences in the relationship between MetS and HRQoL, and also sex differences in the factors associated with HRQoL, the aim of this study was to identify: 1) whether women exhibit greater negative impacts on physical domain HRQoL owing to MetS compared with men; 2) whether women exhibit greater mental domain impacts compared with men; and 3) whether factors associated with HRQoL scores differ between men and women.

\section{Methods}

\section{Ethical statement}

This study was approved by the institutional review board of Taipei Veterans General Hospital, Taipei, Taiwan. Informed consent was obtained from all individuals who participated in the study.

\section{Study design, target population, and participants}

This study was a cross-sectional study conducted in nine neighborhoods in the Shipai area of Taipei, Taiwan during 2009-2010. The inclusion criteria were as follows: (1) residents of Shipai who had lived in the area for at least 6 months, and (2) aged between 35 and 55 years. Potentially eligible participants were identified from the official government household registration system in December 2008 and January 2009. Those who fulfilled with the inclusion criteria were randomly sampled and were sent invitation letters. Individuals who agreed to participate were included after they had signed an informed consent form. Participants then underwent examination 
and answered questionnaires at the research center of Taipei Veterans General Hospital. The response rate was $10.1 \%$. A total of 906 adults participated in this study; of these, $61.7 \%$ were female. The mean age of all participants was $46.9 \pm 5.5$ years, and there was no significant age difference between male and female participants. The mean BMI of participants was $23.8 \pm 3.5 \mathrm{~kg} / \mathrm{m}^{2}$, and mean waist circumference was $83.4 \pm 9.9 \mathrm{~cm}$. A total 37 . $5 \%$ of male participants had waist circumference $\geq$ $90 \mathrm{~cm}$, and $44.5 \%$ of female participants had waist circumference $\geq 80 \mathrm{~cm}$. Compared with women, men had a lower rate of illiteracy or elementary school education $(0.9 \%$ vs. $2.3 \%)$ and a higher rate of university education level and above (69.7\% vs. $57.7 \%, p=0.001)$. A higher percentage of male participants than female ones were married $(89.6 \%$ vs. $82.0 \%, p=0.002)$. There were also significant differences between men and women in terms of smoking status and alcohol consumption. More male participants were current or ex-smokers and current drinkers. With respect to physical activity, there was no significant difference in physical activity levels between male and female participants $(p=0.866)$ (Table 1$)$.

\section{Definitions of components of MetS}

The five components of MetS considered in this study were chosen according to the criteria proposed by the Taiwan National Department of Health in 2007, as follows: (1) central obesity, defined as a waist circumference $\geq 90 \mathrm{~cm}$ for men and $\geq 80 \mathrm{~cm}$ for women; (2) elevated blood pressure, defined as systolic blood pressure $\geq 130 \mathrm{mmHg}$, diastolic blood pressure $\geq 85 \mathrm{mmHg}$, or receiving any specific treatment for hypertension; (3) elevated triglyceride, defined as triglyceride $\geq 150 \mathrm{mg} / \mathrm{dL}$ or receiving any specific treatment for this lipid abnormality; (4) low HDL-C, defined as HDL-C $<40 \mathrm{mg} / \mathrm{dL}$ for males, HDL-C $<50 \mathrm{mg} / \mathrm{dL}$ for females, or receiving any specific treatment for this lipid abnormality; and (5) fasting hyperglycemia, defined as fasting plasma glucose $\geq 100 \mathrm{mg} / \mathrm{dL}$ or previously diagnosed type 2 diabetes [17]. If a person had three or more of the above five components, then they were regarded as having MetS. Accordingly, the number of MetS components for each participant in this study was recorded and subjected to further analysis.

\section{Measurement of HRQoL}

The Short Form Health Survey (SF-36), Taiwan version, which was developed following International Quality of Life Assessment (IQOLA) project protocols $[18,19]$, was used for evaluating HRQoL among participants in this study. This questionnaire was self-administered by participants with the help of trained research assistants at the research center of Taipei Veterans General Hospital. The SF-36 measures eight health domains that can be grouped into two categories under the physical component summary (PCS) and mental component summary (MCS), with overall PCS and MCS scores representing subjective physical health and mental health, respectively. The PCS comprises the four physical health domains of the SF-36: physical functioning (ten items), role limitations owing to physical problems (four items), bodily pain (two items), and general health (five items). The MCS comprises the other four domains, which are mental health domains: vitality (four items), social functioning (two items), role limitations owing to emotional problems (three items), and mental health (five items). Another single item evaluating perceived change in health is also included in the SF-36. Responses to these 36 items are scored according to the scoring instructions provided in the SF-36 Health Survey Manual and Interpretation Guide. For each domain, the score ranges from 0 to 100 , with lower scores indicating more impaired HRQoL. Previous studies revealed that the SF-36 Taiwan version has good validity and reliability with a Cronbach's $\alpha$ of $0.8[18,19]$. The Cronbach's $\alpha$ of SF-36 in this study was 0.68 .

\section{Demographics, medical history, medications, and physical activity}

For each participant, demographic characteristics including sex, age, educational level, marital status, personal habits of cigarette smoking and alcohol consumption, and medical history were recorded using participants' reports. Reported educational level was categorized as illiterate/elementary school, senior/junior high school, or university and above. Reported marital status was categorized as married or single/divorced/separated/ widowed/other. Key aspects of participants' self-reported medical history, including diabetes mellitus, hypertension, and dyslipidemia, were recorded. The medications currently used, including antihypertensive agents, antidiabetic medication (insulin or oral agents), and lipidlowering agents, were noted.

The International Physical Activity Questionnaire (IPAQ) Short-Form, Taiwan version, was used to measure physical activity in this study. Previous studies have reported good validity and reliability of this measurement in Taiwan [20]. This questionnaire was also selfadministered by participants with the help of trained research assistants. The questionnaire consists of seven questions that measure the frequency and/or duration with which a person has engaged in vigorous physical activity, moderate physical activity, walking for at least $10 \mathrm{~min}$ at a time, or sitting, during the previous 7 days. The frequency and/or duration of each specific type of physical activity was computed by weighting its equivalent metabolic equivalent of task (MET), an energy expenditure indicator, to yield an IPAQ score in MET- 
Table 1 Demographic characteristics of participants

\begin{tabular}{|c|c|c|c|c|c|c|c|}
\hline & \multicolumn{2}{|l|}{ Total } & \multicolumn{2}{|l|}{ Men } & \multicolumn{2}{|c|}{ Women } & \multirow[t]{2}{*}{$P$ value } \\
\hline & $n$ & $\%$ & $n$ & $\%$ & $n$ & $\%$ & \\
\hline Sex & & & - & - & - & - & - \\
\hline Men & 347 & 38.3 & - & - & - & - & - \\
\hline Women & 559 & 61.7 & - & - & - & - & - \\
\hline Age $($ mean $\pm S D)$ & 46.9 & 5.5 & 46.9 & 5.7 & 46.9 & 5.5 & 0.884 \\
\hline BMI (mean \pm SD) & 23.8 & 3.5 & 25.2 & 3.3 & 23 & 3.4 & $<0.001$ \\
\hline BMI & & & & & & & $<0.001$ \\
\hline$<18.5$ & 30 & 3.3 & 5 & 1.4 & 25 & 4.5 & \\
\hline $18.5-23.9$ & 492 & 54.3 & 129 & 37.2 & 363 & 64.9 & \\
\hline$\geq 24$ & 384 & 42.4 & 213 & 61.4 & 171 & 30.6 & \\
\hline $\begin{array}{l}\text { Waist circumference } \\
\text { (mean } \pm \mathrm{SD})\end{array}$ & 83.4 & 9.9 & 88.4 & 8.7 & 80.3 & 9.3 & $<0.001$ \\
\hline$<80 \mathrm{~cm}$ & - & - & - & - & 310 & 55.5 & - \\
\hline$\geq 80 \mathrm{~cm}$ & - & - & - & - & 249 & 44.5 & \\
\hline$<90 \mathrm{~cm}$ & - & - & 217 & 62.2 & - & - & \\
\hline$\geq 90 \mathrm{~cm}$ & - & - & 130 & 37.5 & - & - & \\
\hline Education level & & & & & & & 0.001 \\
\hline Illiterate/Elementary school & 16 & 1.8 & 3 & 0.9 & 13 & 2.3 & \\
\hline Senior / Junior high school & 324 & 35.8 & 102 & 29.4 & 222 & 39.9 & \\
\hline University and above & 563 & 62.1 & 242 & 69.7 & 321 & 57.7 & \\
\hline Marital status & & & & & & & 0.002 \\
\hline Married & 764 & 84.3 & 309 & 89.6 & 455 & 82.0 & \\
\hline $\begin{array}{l}\text { Single/Divorced/Separated/ } \\
\text { Widowed/others }\end{array}$ & 136 & 15 & 36 & 10.4 & 100 & 18.0 & \\
\hline \multicolumn{8}{|l|}{ Personal habits } \\
\hline Smoking & & & & & & & $<0.001$ \\
\hline Non-smoker & 723 & 79.8 & 205 & 59.2 & 518 & 93.0 & \\
\hline Current smoker & 125 & 13.8 & 96 & 27.7 & 29 & 5.2 & \\
\hline Ex-smoker & 55 & 6.1 & 45 & 13.0 & 10 & 1.8 & \\
\hline Alcohol consumption & & & & & & & $<0.001$ \\
\hline No & 765 & 84.4 & 240 & 69.2 & 525 & 94.3 & \\
\hline Yes & 139 & 15.3 & 107 & 30.8 & 32 & 5.7 & \\
\hline Physical activity (IPAQ score) & & & & & & & 0.866 \\
\hline Low & 318 & 35.1 & 120 & 34.6 & 198 & 35.4 & \\
\hline Moderate & 403 & 44.5 & 153 & 44.1 & 250 & 44.7 & \\
\hline High & 185 & 20.4 & 74 & 21.3 & 111 & 19.9 & \\
\hline
\end{tabular}

minutes. The sum of MET-minutes, in turn, represents the overall volume of activity. Vigorous physical activity refers to activities with a value of 8 METs that require intense physical effort and make the person breathe much harder than normal; moderate physical activities refer to activities with a value of 4 METs that require moderate physical effort and make the person breathe somewhat harder than normal; walking is calculated as having a value of 3.3 METs. Accordingly, participants were stratified into three levels of physical activity according to their overall volume and frequency of activity: low, moderate, and high. A high level of physical activity refers to: (1) doing vigorous physical activities for at least 3 days, adding up to at least 1500 MET-minutes/week or (2) doing a combination of vigorous physical activities, moderate physical activities, and/or walking for at least 7 days adding up to at least 3000 MET-minutes/week. A moderate level of physical activity refers to: (1) doing 
vigorous physical activities for at least 20 min per day for at least 3 days, (2) doing moderate physical activities or walking for at least $30 \mathrm{~min}$ per day for at least 5 days, or (3) doing a combination of vigorous physical activities, moderate physical activities, or walking for at least 5 days adding up to at least $600 \mathrm{MET}$-minutes/week. A low level of physical activity refers to any level of activity not meeting the above criteria for high and moderate levels.

\section{Anthropometry, blood pressure, and blood tests}

The body weight, height, body mass index (BMI), waist circumference, and systolic and diastolic blood pressure of each participant were measured and recorded. Height and weight were evaluated using an automatic electronic measuring device, and BMI was obtained via calculation. Waist circumference was measured by the standard method. Blood pressure was measured using a standardized sphygmomanometer applied with the participant in a seated position, after $30 \mathrm{~min}$ of rest.

Each participant fasted for at least $8 \mathrm{~h}$ before the collection of blood samples. Blood tests including fasting plasma glucose, triglycerides, and HDL-C were conducted at the central laboratory of Taipei Veterans General Hospital, which has obtained laboratory accreditation/certification from the College of American Pathologists.

\section{Statistical analysis}

Statistical analyses were performed using Microsoft Excel (2016) and IBM SPSS, version 20.0 (IBM Corporation, Armonk, NY, USA). All analyses were stratified by sex. Descriptive statistics are presented as means and standard deviations for continuous variables, and as numbers and percentage for categorical variables. The differences between means were evaluated using a Student $t$-test (continuous variables with 2 categories) or analysis of variance (ANOVA) (continuous variables with $\geq 3$ categories); the differences between categorical variables were evaluated using the chi-square test. Comparisons of HRQoL scores across physical activity groups were performed by ANOVA. Multiple linear regression models were used to determine the associations between covariates and PCS and MCS quality of life scores for all male and female participants. Covariates entered in the models included sex, age, education level, marital status, number of MetS components, physical activity level, and personal habits of smoking and alcohol consumption. For education level, we coded illiterate/elementary school as the reference level whereas for physical activity, we coded low physical activity as the reference level. A two-tailed $p$ value $<0.05$ was considered statistically significant.

\section{Results}

Table 2 shows the sex differences in the components of MetS and SF-36 scores. Men had significantly higher proportions of high blood pressure compared with women (both systolic BP [47.8\% vs. $21.6 \%, p<0.001]$ and diastolic BP [ $40.3 \%$ vs. $16.8 \%, p<0.001]$ ). A significantly higher proportion of male participants demonstrated abnormal triglyceride levels ( $34.3 \%$ vs. $14.9 \%, p$ $<0.001)$ and fasting hyperglycemia than female participants $(24.8 \%$ vs. $15.4 \%, p<0.001)$. A significantly higher percentage of women had a large waist circumference (49. $2 \%$ vs. $40.9 \%, p=0.015)$. In terms of SF-36 scores, female participants had significantly lower scores than male ones in physical functioning $(52.4 \pm 5.3$ vs. $54.2 \pm 4.4, p<0.001)$, role limitations owing to physical problems ( $51.3 \pm 8.3$ vs. $52.6 \pm 7.7, p=0.022)$, bodily pain ( $52.3 \pm 8.1$ vs. $53.9 \pm 8.3$, $p=0.003)$, mental health ( $38 \pm 4.5$ vs. $39.3 \pm 4.3, p<0.001)$, and PCS score $(54.1 \pm 6.9$ vs. $55.7 \pm 6.7, p<0.001)$.

Table 3 presents the results of regression analyses of the PCS scores. For all participants, men had significantly higher PCS scores than women $(\beta=1.353, p=0.012)$; participants with more MetS components had significantly lower PCS scores $(\beta=-0.371, p=0.043)$. Other significant factors associated with higher PCS scores including higher education level and higher physical activity level; current smokers had significantly lower PCS scores, and exsmokers had higher PCS scores than non-smokers. For the different sexes, male participants with an education level of university/above had higher PCS scores than those who were illiterate or had an elementary school education $(\beta=17.02)$. Similarly, men with a high school education had higher PCS scores than those who were illiterate or only completed elementary school $(\beta=17.686)$. The table also shows that male participants with moderate and high physical activity had significantly higher PCS scores than those with low physical activity $(\beta=2.203$, $p=0.005$ and $\beta=3.370, p=0.001$, respectively). Interestingly, ex-smoker status was positively correlated with PCS scores whereas current smoker status was inversely correlated ( $\beta=2.521$ and -1.721 , respectively) in relation to non-smoker status. Among women, older age and number of components of MS were significantly associated with lower PCS score $(\beta=-0.114, p=0.041$ and $\beta=-0.542, p=$ 0.036 , respectively); however, education and physical activity levels were not significantly associated with PCS scores.

Table 4 presents the results of regression analyses of the MCS scores. For all participants, sex and number of MetS components were not significantly associated with MCS scores. However, participants with a high schoollevel education had significantly lower MCS scores than those who were illiterate or only completed elementary school $(\beta=-2.590, p=0.042)$. Participants who were current smokers and consumed alcohol had significantly lower MCS scores than non-smokers and non-drinkers $(\beta=-1.394, p=0.009$ and $\beta=-1.173, p=0.020$, respectively). As for the different sexes, male participants with a high school education level had lower MCS scores than 
Table 2 Components of metabolic syndrome and SF-36 scores of participants

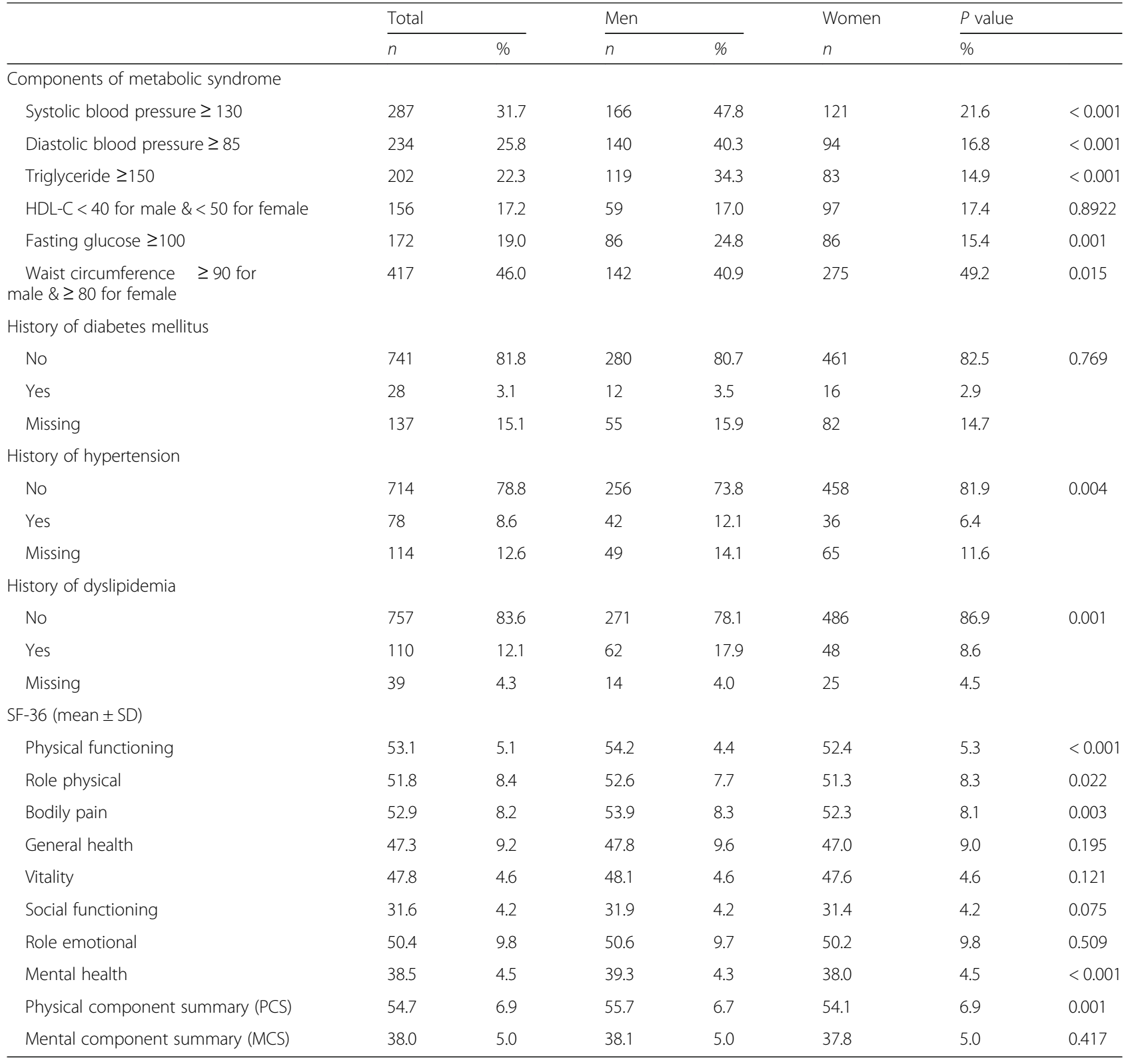

those who were illiterate or had an elementary school education $(\beta=-5.761$. In addition, married men had significantly higher MCS scores $(\beta=2.837, p=0.001)$, and males who reported alcohol consumption had significantly lower MCS scores $(\beta=-1.293, p=0.03)$. Among female participants, current smoking was inversely correlated with MCS scores $(\beta=-2.322, p=0.019)$.

\section{Discussion}

In this study, after adjusting for covariates, we found that women but not men with more MetS components had significantly lower PCS scores. The results also showed significant sex differences in several dimensions, including education level, physical activity level, and smoking status for PCS scores; and education level, smoking status, and alcohol consumption for MCS scores.

Some studies have reported that declining physical HRQOL is accompanied by a greater number of MetS components in women but not in men [14, 21]. Katano et al. found that the number of MetS components was inversely associated with general health and positively associated with mental health in both sexes [15]. Although most previous studies have found that MS components are associated with worse HRQoL [15, 22], the reported associations between MetS components and HRQoL in the different sexes have been inconsistent.

A prospective study of middle-aged women in the United States showed that weight gain was associated 
Table 3 Multiple linear regression model for correlates of SF-36 PCS score

\begin{tabular}{|c|c|c|c|c|c|c|}
\hline \multirow[t]{2}{*}{ Covariates } & \multicolumn{2}{|l|}{ Total } & \multicolumn{2}{|l|}{ Males } & \multicolumn{2}{|l|}{ Females } \\
\hline & Beta & $P$ value & Beta & $P$ value & Beta & $P$ value \\
\hline \multicolumn{7}{|l|}{ Demographics } \\
\hline Sex (male vs. female) & 1.353 & 0.012 & - & - & - & - \\
\hline Age (year) & -0.081 & 0.051 & -0.007 & 0.912 & -0.114 & 0.041 \\
\hline \multicolumn{7}{|l|}{ Education level } \\
\hline Illiterate/elementary school & Reference & & Reference & & Reference & \\
\hline High school & 3.43 & 0.047 & 17.02 & $<0.001$ & -0.035 & 0.986 \\
\hline University and above & 4.724 & 0.006 & 17.686 & $<0.001$ & 1.588 & 0.418 \\
\hline Marital status (married vs. others) & -0.197 & 0.757 & 0.591 & 0.607 & -0.382 & 0.62 \\
\hline No. of component of metabolic syndrome & -0.371 & 0.043 & -0.116 & 0.645 & -0.542 & 0.036 \\
\hline \multicolumn{7}{|l|}{ Physical activity level } \\
\hline Low & Reference & & Reference & & Reference & \\
\hline Moderate & 0.897 & 0.076 & 2.203 & 0.005 & 0.101 & 0.878 \\
\hline High & 2.09 & 0.001 & 3.37 & 0.001 & 1.22 & 0.137 \\
\hline \multicolumn{7}{|l|}{ Personal habits } \\
\hline \multicolumn{7}{|l|}{ Smoking } \\
\hline Current smoker vs. non-smoker & -1.675 & 0.02 & -1.721 & 0.036 & -1.084 & 0.421 \\
\hline Ex-smoker vs. non-smoker & 2.451 & 0.014 & 2.521 & 0.019 & 2.393 & 0.276 \\
\hline Alcohol consumption (yes vs. no) & 1.163 & 0.087 & 0.483 & 0.536 & 2.442 & 0.055 \\
\hline
\end{tabular}

Table 4 Multiple linear regression model for correlates of SF-36 MCS score

\begin{tabular}{|c|c|c|c|c|c|c|}
\hline \multirow[t]{2}{*}{ Covariates } & \multicolumn{2}{|l|}{ Total } & \multicolumn{2}{|l|}{ Males } & \multicolumn{2}{|l|}{ Females } \\
\hline & Beta & $P$ value & Beta & $P$ value & Beta & $P$ value \\
\hline \multicolumn{7}{|l|}{ Demographics } \\
\hline Sex (male vs. female) & 0.702 & 0.079 & - & - & - & - \\
\hline Age (year) & 0.056 & 0.069 & 0.073 & 0.124 & 0.028 & 0.49 \\
\hline \multicolumn{7}{|l|}{ Education level } \\
\hline Illiterate/elementary school & Reference & & Reference & & Reference & \\
\hline High school & -2.59 & 0.042 & -5.761 & 0.043 & -1.727 & 0.231 \\
\hline University and above & -2.315 & 0.069 & -4.778 & 0.091 & -1.901 & 0.183 \\
\hline Marital status (married vs. others) & 0.789 & 0.094 & 2.837 & 0.001 & -0.058 & 0.918 \\
\hline No. of component of metabolic syndrome & 0.121 & 0.369 & -0.023 & 0.903 & 0.269 & 0.156 \\
\hline \multicolumn{7}{|l|}{ Physical activity level } \\
\hline Low & Reference & & Reference & & Reference & \\
\hline Moderate & -0.286 & 0.444 & -0.611 & 0.302 & -0.08 & 0.868 \\
\hline High & -0.769 & 0.098 & -1.06 & 0.149 & -0.335 & 0.578 \\
\hline \multicolumn{7}{|l|}{ Personal habits } \\
\hline \multicolumn{7}{|l|}{ Smoking } \\
\hline Current smoker vs. non-smoker & -1.394 & 0.009 & -0.939 & 0.132 & -2.322 & 0.019 \\
\hline Ex-smoker vs. non-smoker & 0.614 & 0.402 & 0.800 & 0.327 & 0.776 & 0.63 \\
\hline Alcohol consumption (yes vs. no) & -1.173 & 0.02 & -1.293 & 0.03 & -0.784 & 0.401 \\
\hline
\end{tabular}


with decreased physical functioning and vitality, as well as increased body pain, regardless of baseline weight [23]. In other recent studies, obesity was usually documented as being associated with poor HRQoL, not only in the physical but also in the mental domain [24, 25]. In our study, a trend indicating that higher numbers of MetS components were accompanied by lower physical health scores was found in women but not in men, indicating other mechanisms that are associated with this sex difference might deserve further investigation.

Although recent studies have demonstrated that dietary modification and enhanced physical activity may delay or prevent the transition from impaired glucose tolerance to type 2 diabetes mellitus and provide an adequate lifestyle for obese people [26], physical activity is probably not the most influential factor in MetS, or MetS may be affected by many factors. When adjustments for other lifestyle factors were made, we found significant associations between physical activity levels and physical health scores among men who participated in our study. Specifically, men who had insufficient physical activity had worse PCS scores than those with both moderate and high levels of physical activity; this finding was in line with previous studies [27, 28]. People with impaired HRQoL may also be less likely to participate in physical activity. On the other hand, it is possible that physical activity can improve HRQoL. However, because this was a cross-sectional research study, we could not determine any cause-effect relationship.

Some studies have found that physical activity most directly affects HRQoL through its impact on psychological well-being or emotional function [29]. Results from the Alameda County Study also suggest that people with low physical activity levels have a higher risk for depression compared with those who have higher levels of physical activity, independent of the presence of chronic conditions [30]. In our study, there was no difference in mental health scores between the sexes. More studies might be required to determine possible mechanisms explaining the relationship between physical activity and mental health.

In our study, we noted that male current smokers had significantly lower PCS scores whereas female current smokers had lower MCS scores than non-smokers. In addition, we noted that males who had quit smoking had better PCS scores than non-smokers. As we know, cigarette smoking plays a substantial role in the pathogenesis of numerous chronic diseases such as cardiovascular, cancer, lung, and other diseases [31, 32]. Thus, quitting smoking is a healthy behavior that can elevate not only HRQoL but also improve the environment, allowing others to feel more comfortable. Regarding alcohol consumption, the results in our study were line with those of several previous studies that also found that consuming alcohol was associated with poor HRQoL [33-37], especially for males [38]. The relationship between alcohol consumption and HRQoL is complex. Possible mechanisms included alcohol-related medical conditions, mental disorders, social problems, accidents, and violence. Our results suggest that maintaining healthy behaviors can lead to better HRQoL.

The significant positive association between high education levels and PCS score and the negative association between education levels and MCS score were found in males but not females. Sex differences in the associations between education level and PCS and MCS scores might be complicated. People with higher education levels might have better health knowledge, which could be helpful in maintaining healthy behaviors, disease prevention, and seeking professional medical treatment [39-41], all of which positively influence physical healthrelated quality of life. For mental health-related quality of life score, the negative associations might be related to stress from various aspects of daily life such as family issues, work competition, and so on. Males who were married had significantly higher MCS scores, which might be related to having better family supports.

The results of this analysis have some limitations. The analysis was cross-sectional in nature, such that making determinations about cause and effect is impossible. Furthermore, the sample in our study was local and too small to be representative of the entire population of Taiwan. In addition, mechanisms of the sex differences found in the associations between HRQoL and MS are unclear; these might be both biological and psychosocial. It is possible that sex variations in health-related behaviors (e.g., physical activity, smoking, alcohol consumption) may have many different kinds of impact on HRQoL outcomes. There are also differences in symptom presentation and management between men and women that could affect their perceptions of HRQoL. Thus, the sex differences in HRQoL require further study. However, to our knowledge, there have been few previous studies on the association between HRQoL and MS in Asian countries, especially in Taiwan. Our study was the first of its type to consider a middle-aged population in Taiwan, and the findings should allow us to better understand the health burden of MS among Taiwanese adults. A clearer finding of sex differences related to the association between MS and HRQoL will offer more information, to improve HRQoL of the population in the future.

\section{Conclusion}

The results of this study showed that, after adjusting for covariates, women but not men with more MetS components had significantly lower PCS scores. The number of MetS components was not a significant factor of MCS scores between sexes. Furthermore, there 
were sex differences regarding age, education level, physical activity, and smoking status in association with PCS scores. For MCS scores, sex differences were found in education level, marital status, and habits of smoking and alcohol consumption. Further research should be conducted to investigate mechanisms of these sex differences.

\section{Abbreviations}

BMI: Body mass index; HRQoL: Health-related quality of life; IPAQTaiwan: International physical activity questionnaire Taiwan version; IQOLA: International quality of life assessment; MCS: Mental component summary; MET: Metabolic equivalent of task; MetS: Metabolic syndrome; PCS: Physical component summary; SF-36 Taiwan: Short form-36 Taiwan version

\section{Acknowledgements}

We thank all study participants for their willingness to provide data for this research project, and we are indebted to all coworkers for their enthusiastic commitment.

\section{Funding}

This study was supported in part by grants from the Taipei Veterans General Hospital, Taiwan (V96S3-001, - 002, - 005; V97S3-001, - 002, - 005; V98S3001, - 002, - 005; V99S3-001, - 002, - 005;106-E-005-2)

\section{Availability of data and materials}

The datasets generated during and/or analyzed during the current study are not publicly available because the local ethics committee requested to protect the participant privacy.

\section{Authors' contributions}

$\mathrm{CCL}$ wrote the first draft of the paper, with contribution from $\mathrm{SJH}$ and HTC. The data analyses and interpretation were completed by CCL, HTC and SCC. HTC and SJH revised the manuscript and gave the final approval to submit the manuscript for publication. All authors contributed to study design and conduct of the study, and contributed to the final manuscript. All authors have read and approved the final manuscript.

\section{Ethics approval and consent to participate}

This study was approved by the institutional review board of Taipei Veterans General Hospital, Taipei, Taiwan (97-12-06A and 2017-01-009BCF). All procedures performed in studies involving human participants were in accordance with the ethical standards of the institutional and/or national research committee and with the 1964 Helsinki declaration and its later amendments or comparable ethical standards. Informed consent was obtained from all individual participants included in the study.

\section{Competing interests}

The authors declare that they have no competing interests.

\section{Publisher's Note}

Springer Nature remains neutral with regard to jurisdictional claims in published maps and institutional affiliations.

\footnotetext{
Author details

'Division of Family Medicine, Department of Medicine, Kaohsiung Veterans General Hospital Pingtung Branch, No.1, Anping Lane 1, Jausheng Rd, Neipu Township, Pingtung, Taiwan. ${ }^{2}$ Department of Family Medicine, Taipei Veterans General Hospital, No. 201, Section 2, Shipai Road, Beitou District, Taipei, Taiwan. ${ }^{3}$ School of Medicine, National Yang-Ming University, Taipei, Taiwan. ${ }^{4}$ Institute of Hospital and Health Care Administration, National Yang-Ming University, Taipei, Taiwan. ${ }^{5}$ Division of Endocrinology and Metabolism, Department of Medicine, Taipei Veterans General Hospital, No. 201, Sec. 2, Shipai Road, Beitou District, Taipei, Taiwan.
}

Received: 26 August 2017 Accepted: 23 April 2018

Published online: 27 April 2018

\section{References}

1. Alberti KG, Zimmet P, Shaw J. The metabolic syndrome-a new worldwide definition. Lancet. 2005;366:1059-62.

2. Chen J, Muntner P, Hamm LL, Jones DW, Batuman V, Fonseca V, et al. The metabolic syndrome and chronic kidney disease in US adults. Ann Intern Med. 2004;140:167-74

3. Malik S, Wong ND, Franklin SS, Kamath TV, Gilbert J, Pio JR, et al. Impact of the metabolic syndrome on mortality from coronary heart disease, cardiovascular disease, and all causes in United States adults. Circulation. 2004:110:1245-50.

4. Ford ES. Risks for all-cause mortality, cardiovascular disease, and diabetes associated with the metabolic syndrome. Diabetes Care. 2005;28:1769-78.

5. Grundy SM, Cleeman JI, Daniels SR, Donato KA, Eckel RH, Franklin BA, et al. Diagnosis and management of the metabolic syndrome. Circulation. 2005; $112 \cdot 2735-52$

6. Ford ES, Giles WH, Mokdad AH. Increasing prevalence of the metabolic syndrome among US adults. Diabetes Care. 2004:27:2444-9.

7. Miller JM, Kaylor MB, Johannsson M, Bay C, Churilla JR. Prevalence of metabolic syndrome and individual criterion in US adolescents: 2001-2010 National Health and nutrition examination survey. Metab Syndr Relat Disord. 2014; 12:527-32.

8. Li R, Li W, Lun Z, Zhang H, Sun Z, Kanu JS, et al. Prevalence of metabolic syndrome in mainland China: a meta-analysis of published studies. BMC Public Health. 2016;16:296

9. Yeh CJ, Chang HY, Pan WH. The investigation on the changes of obesity and metabolic syndrome in Taiwan: nutrition and health survey in Taiwan between 1993 to 1996 and 2005 to 2008. Accessed 27 June 2017. [https:// obesity.hpa.gov.tw/TC/researchList.aspx?pn=1\&cid=163].

10. Urashima M, Wada T, Fukumoto T, Joki M, Maeda T, Hashimoto H, et al. Prevalence of metabolic syndrome in a 22,892 Japanese population and its associations with life style. J MAJ. 2005;48:441-50.

11. Yeh CJ, Chang HY, Pan WH. Time trend of obesity, the metabolic syndrome and related dietary pattern in Taiwan: from NAHSIT 1993-1996 to NAHSIT 2005-2008. Asia Pac J Clin Nutr. 2011;20:292-300.

12. The World Health Organization Quality of Life Assessment. (WHOQOL): development and general psychometric properties. Soc Sci Med. 1998; 46:1569-85

13. World Health Organization. Preamble to the constitution of the World Health Organization, as adopted by the International Health Conference. New York, pp. 19-22 (June 1946): signed on 22 July 1946 by the representatives of 61 states,(official Records of the World Health Organization, no. 2 p. 100). and Enterd into Force on. April 1948;7:1948.

14. Amiri P, Hosseinpanah F, Rambod M, Montazeri A, Azizi F. Metabolic syndrome predicts poor health-related quality of life in women but not in men: Tehran lipid and glucose study. J Women's Health. 2010;19:1201-7.

15. Katano S, Nakamura Y, Nakamura A, Suzukamo Y, Murakami Y, Tanaka T, et al. Relationship between health-related quality of life and clustering of metabolic syndrome diagnostic components. Qual Life Res. 2012;21: 1165-70

16. Sohn YJ, Sohn HS, Kwon JW. Gender differences among middle-aged Koreans for health-related quality of life related to metabolic syndrome. Qual Life Res. 2011;20:583-92.

17. Health Promotion Administration. The definition of the metabolic syndrome of adults in Taiwan. http://www.hpa.gov.tw/Pages/Detail.aspx?nodeid= 639\&pid=1219. Accessed 30 Jan 2015.

18. Lu J, Tseng H, Tsai Y. Assessment of health-related quality of life in Taiwan (I): development and psychometric testing of SF-36 Taiwan version. Taiwan J Public Health. 2003:22:501-11.

19. Tseng H, Lu J, Tsai Y. Assessment of health-related quality of life in Taiwan (II): norming and validation of SF-36 Taiwan version. Taiwan. J Public Health 2003;22:512-8

20. Liou YM, Jwo CJ, Yao KG, Chiang LC, Huang LH. Selection of appropriate Chinese terms to represent intensity and types of physical activity terms for use in the Taiwan version of IPAQ. J Nurs Res. 2008;16:252-63.

21. Levinger I, Goodman C, Hare DL, Jerums G, Selig S. Functional capacity and quality of life in middle-age men and women with high and low number of metabolic risk factors. Int J Cardiol. 2009;133:281-3. 
22. Tziallas D, Kastanioti C, Kostapanos MS, Skapinakis P, Elisaf MS, Mavreas V. The impact of the metabolic syndrome on health-related quality of life: a cross-sectional study in Greece. Eur J Cardiovasc Nurs. 2012;11:297-303.

23. Fine JT, Colditz GA, Coakley EH, Moseley G, Manson JE, Willett WC, et al. A prospective study of weight change and health-related quality of life in women. JAMA. 1999;282:2136-42.

24. Taylor VH, Forhan M, Vigod SN, McIntyre RS, Morrison KM. The impact of obesity on quality of life. Best Pract Res Clin Endocrinol Metab. 2013;27:139-46.

25. Warkentin L, Das D, Majumdar S, Johnson J, Padwal R. The effect of weight loss on health-related quality of life: systematic review and meta-analysis of randomized trials. Obes Rev. 2014;15:169-82.

26. Tuomilehto J, Lindström J, Eriksson JG, Valle TT, Hämäläinen H, llanneParikka P, et al. Prevention of type 2 diabetes mellitus by changes in lifestyle among subjects with impaired glucose tolerance. N Engl J Med. 2001;344: 1343-50.

27. Vuillemin A, Boini S, Bertrais S, Tessier S, Oppert J-M, Hercberg S, et al. Leisure time physical activity and health-related quality of life. Prev Med. 2005:41:562-9.

28. Jurakić $\mathrm{D}$, Pedišić Ž, Greblo Z. Physical activity in different domains and health-related quality of life: a population-based study. Qual Life Res. 2010; 19(9):1303.

29. Rejeski WJ, Brawley LR, Shumaker SA. Physical activity and health-related quality of life. Exerc Sport Sci Rev. 1996;24:71-108.

30. Strawbridge WJ, Deleger S, Roberts RE, Kaplan GA. Physical activity reduces the risk of subsequent depression for older adults. Am J Epidemiol. 2002; 156:328-34.

31. Katsiki N, Papadopoulou SK, Fachantidou Al, Mikhailidis DP. Smoking and vascular risk: are all forms of smoking harmful to all types of vascular disease? Public Health. 2013;127:435-41.

32. Kolovou GD, Kolovou V, Mavrogeni S. Cigarette smoking/cessation and metabolic syndrome. J Clin Lipidol. 2016;11:6-14.

33. Savolainen J, Kautiainen H, Miettola J, Niskanen L, Mantyselka P. Low quality of life and depressive symptoms are connected with an unhealthy lifestyle. Scand J Public Health. 2014;42:163-70.

34. Daeppen JB, Faouzi M, Sanchez N, Rahhali N, Bineau S, Bertholet N. Quality of life depends on the drinking pattern in alcohol-dependent patients. Alcohol Alcohol. 2014;49:457-65.

35. Kaplan MS, Huguet N, Feeny D, McFarland BH, Caetano R, Bernier J, et al. Alcohol use patterns and trajectories of health-related quality of life in middle-aged and older adults: a 14-year population-based study. J Stud Alcohol Drugs. 2012;73:581-90.

36. Chen CY, Storr CL. Alcohol use and health-related quality of life among youth in Taiwan. J Adolesc Health 2006;39. 752:e9-16.

37. Frischknecht $\mathrm{U}$, Sabo T, Mann K. Improved drinking behaviour improves quality of life: a follow-up in alcohol-dependent subjects 7 years after treatment. Alcohol Alcohol. 2013;48:579-84.

38. Mathiesen EF, Nome S, Eisemann M, Richter J. Drinking patterns, psychological distress and quality of life in a Norwegian general populationbased sample. Qual Life Res. 2012;21:1527-36.

39. Wieder-Huszla S, Szkup M, Jurczak A, Samochowiec A, Samochowiec J, Stanislawska M, et al. Effects of socio-demographic, personality and medical factors on quality of life of postmenopausal women. Int J Environ Res Public Health. 2014;11:6692-708.

40. Ose D, Rochon J, Campbell SM, Wensing M, Freund T, van Lieshout J, et al. Health-related quality of life and risk factor control: the importance of educational level in prevention of cardiovascular diseases. Eur J Pub Health. 2014;24:679-84.

41. Kosilov K, Loparev S, Kuzina I, Kosilova L, Ivanovskaya M, Prokofyeva A. Health-related quality of life's dependence on socio-economic status and demographic characteristics among men with benign prostatic hyperplasia. Andrologia. 2018; https://doi.org/10.1111/and.12892.

Ready to submit your research? Choose BMC and benefit from:

- fast, convenient online submission

- thorough peer review by experienced researchers in your field

- rapid publication on acceptance

- support for research data, including large and complex data types

- gold Open Access which fosters wider collaboration and increased citations

- maximum visibility for your research: over $100 \mathrm{M}$ website views per year

At BMC, research is always in progress.

Learn more biomedcentral.com/submissions 